\title{
EXPERIENCIA, TÉCNICA Y TERRITORIO EN EL DOCUMENTAL CHILENO DE FINES DE LOS CINCUENTA*
}

\author{
Pablo Corro Penjean**
}

\begin{abstract}
Resumen
Este trabajo advierte sobre el singular vuelco hacia el protagonismo retórico de la experiencia subjetiva que manifiestan algunos documentales chilenos a finales de los años cincuenta. La emancipación de la "modalidad expositiva" dominante en ese medio que representan particularmente los filmes Mimbre (1957) y Andacollo (1958), implica tanto una conciencia exacerbada y explícita de la técnica de representación, como figuraciones inusitadas del territorio argumental local. Finalmente, el texto interpreta esas diversas innovaciones como efectos de un debilitamiento de las representaciones políticas generales de la nación y el estado a causa de los progresivos fracasos de los gobiernos precedentes.
\end{abstract}

Palabras clave: Cine documental chileno, Sergio Bravo, Nieves Yankovic y Jorge Di Lauro, experiencia, representación técnica, territorio.

\section{EXPERIENCIE, TECHNIQUE, AND TERRITORY IN CHILEAN DOCUMENTARIES OF THE LATE FIFTIES}

\begin{abstract}
This paper points out the singular twirl towards the rhetoric leadership of subjective experience that some Chilean documentaries manifest in the late fifties. The emancipation of the dominant "expositive modality" in this medium, that are particularly represented by the films Mimbre (1957) and Andacollo (1958), entails an exacerbated and explicit awareness of the representation technique as well as unusual figurations of the argumentative local territory. Finally, the article interprets those diverse innovations as consequences of a weakening in the general political representations of the nation and the state because of the progressive failures of previous governments.
\end{abstract}

Keywords: Chilean documentary, Sergio Bravo, Nieves Yankovic y Jorge Di Lauro, experience, technical representation, territory.

* El presente artículo forma parte de las indagaciones del Proyecto Fondecyt Regular $\mathrm{N}^{\circ} 1160219$ titulado Imágenes de Técnicas en el Cine Documental Latinoamericano: Motivos de Modernidad y Territorio. El autor del artículo, Investigador Responsable del proyecto, agradece a nombre de todo el equipo, a Conicyt-Fondecyt por permitirnos, con su financiamiento y orientaciones, llevar a cabo las pesquisas que nos trazamos, las reflexiones consecuentes y las diversas acciones de divulgación de los resultados.

** Chileno, Doctor en Filosofía de la Universidad de Barcelona, España. Profesor Asociado del Instituto de Estética de la Facultad de Filosofía de la Pontificia Universidad Católica de Chile, Santiago, Chile. pablo.corro@gmail.com. 


\section{La liberación de la "objetividad" y el descubrimiento de la "experiencia"}

En su misterioso texto breve de 1945 Ontología de la imagen fotográfica, el crítico de cine André Bazin sostiene que "la fotografía se nos aparece así como el acontecimiento más importante de la historia de las artes plásticas. Siendo a la vez una liberación y una culminación, ha permitido a la pintura occidental liberarse definitivamente de la obsesión realista y recobrar su autonomía estética" (30). Según él mismo señala, puesto que "en esta perspectiva, el cine se nos muestra como la realización en el tiempo de la objetividad fotográfica" (Bazin: 30), es de suponer que conforme a este predicamento de liberaciones posibilitadas por el progreso técnico el cine también contribuye a la liberación de la pintura de la esclavitud mimética y a la temprana emancipación de la fotografía misma que en la década del veinte emprenden sujetos como Man Ray o Moholo Nagy.

Tendríamos que estudiar si es que la televisión en la década de los cincuenta representó una oportunidad de liberación del realismo para el cine, previendo argumentos a favor y en contra. Por ejemplo, a favor, se puede considerar la evidencia de que el gran acontecimiento cinematográfico de referencialidades sociales críticas que fue el "neorrealismo italiano" gira hacia indagaciones sicológicas o formalistas estéticas justo a mediados de los cincuenta, por ejemplo, a través de Antonioni. Ese giro contiene referencias explícitas al aparato que ha dispuesto las imágenes objetivas y activas del mundo en el salón de la casa o en la cocina a la hora del almuerzo. Un argumento en contra es que es poco probable que la televisión de los años cincuenta haya satisfecho mejor que el cine las visiones miméticas e informativas del mundo presente, puesto que el logro técnico y la cultura de lo "en directo" exterior -o "en vivo"- era aún menos relevante que las escenificaciones y coloquios de estudio.

Este pensamiento acerca de un medio de representación técnica visual -o audiovisual- que se libera de la referencialidad figurativa e informativa del mundo, por la acción de otro que la cumple de forma más completa y convincente, la proponemos como prólogo del planteamiento relativo a dos documentales chilenos de fines de la década de los cincuenta que liberan a su medio del hábito dominante de la exposición informativa del mundo y que lo hacen mediante una evidencia explícita 
de la recursividad técnica implicada en el gesto, pero configurando a éste mismo como efecto de subjetividad. Nos referimos a los bellos cortometrajes Mimbre de Sergio Bravo (1957), y a Andacollo, de Nieves Yankovic y Jorge Di Lauro (1958). Uno y otro se liberan de la pretensión objetiva, no tanto porque renuncien al narrador over, trascendental, impreso con la música sobre la banda de imágenes como ocurre en el modo observacional de Mimbre, o a través de la narradora-autora-personaje como en Andacollo, donde Nieves Yankovic afirma participar de la fiesta religiosa descrita -tal como un relator off-, sino justamente porque ambos documentales ofrecen como objeto la experiencia personal de un fenómeno, respectivamente el de la visión del tejido del mimbre a la luz del sol y el de la vivencia de la fiesta de la Virgen de Andacollo, el 25 de diciembre. Ambos fenómenos expresivos de formas de la cultura popular tradicional se proponen como culturalmente admisibles para una objetividad escópica técnica formalmente experimental y no pintoresca, o para una visión que ensaya, como virtud política del medio de exposición, pensar el espacio dramático como espacio cultural válido, como territorio cinematográfico autosuficiente.

Una manera de sintetizar estas diversas conjeturas es postulando que estos documentales presentan un giro del género hacia la experiencia. Los créditos de obertura de Mimbre señalan "En la Quinta Normal, calle Abtao 275, vive Alfredo 'manzanito', hijo de pescadores y virtuoso en el arte de tejer mimbre. En este documental solo queremos dar a conocer las impresiones visuales que sacuden al visitante que llega a su taller". Si el asunto argumental acotado al estremecimiento de la visión respecto de la operación manual y sus efectos ópticos depende de la mediación cinematográfica, ese hecho como subjetividad afirmada por la técnica se corresponde con la explícita focalización territorial del cortometraje en que la visión nueva realza el espacio dramático de un antiguo barrio céntrico circunscribiéndolo como escenario fenoménico singular. La modernidad del gesto es la libertad de expresar técnicamente la subjetividad frente al objeto artesanal y de legitimarlo como figurante de un centro dramático fílmico, pese a su periferia social.

En este mismo sentido de patentizar técnicamente la subjetividad, la primera locución de Nieves Yankovic en Andacollo expresa que "este documental es un homenaje a la coronada reina de la montaña". En nuestra línea argumental, el homenaje mismo como hecho espiritual, como 
forma retórica devocional incluye o, acaso depende en gran medida, del esfuerzo cinematográfico de exposición, de la orientación productiva hacia el tópico mariano.

En una entrevista a Sergio Bravo realizada por los investigadores Claudio Salinas y Hans Stange (2008), el realizador confirma la determinación objetual de la experiencia fotográfica

¡Filmando descubrimos el quehacer mágico de Alfredo Manzano y al proyectar las imágenes filmadas comprobamos que el hecho de asumir la mirada propia es algo esencial en la expresión audiovisual documental: Asumir la propia mirada! Las revelaciones sorprendentes que nos traía la luz en las imágenes nos obligaron a continuar la experimentación. (55)

En la línea de admitir la legitimidad de lo documental subjetivo, un columnista de la Revista Ecran escribe en 1960 sobre Andacollo:

Por primera vez, desde los trabajos del Centro de cine experimental (Mimbre, Trilla, Día de organillos) ${ }^{1}$, este documental chileno evita la mera filmación de paisajes y la descripción superficial buscando un mayor contenido. Andacollo, de 16 mm, color, 20 minutos, de Jorge Di Lauro, interpreta la fiesta de N.S. de Andacollo, desde un punto de vista distinto y personal. (Cit. en Vega 167)

El vuelco hacia la experiencia debe ser comprendido, prioritariamente, como un giro hacia el protagonismo estético de la vivencia de la dimensión subjetiva, que en el caso de Mimbre es el de la sensorialidad dinámica, sonora, temporal y táctil, agitada por la visualidad luminosa de las activas tramas de luz y sombra que componen las varas trenzadas bajo la claridad solar por el artesano Manzanito, el de una sinestesia provocada por la dinámica cámara explícita, agitada por las cantidades de luz -diría Deleuze (2008) a propósito de esta edición fílmica en sus teorías del montaje-. En el caso de Andacollo es la experiencia del entusiasmo más propio, del entusiasmo religioso motivado por la vista cinematográfica de las caminatas afanosas de los peregrinos atravesando los cerros

1 Los cortometrajes documentales Trilla y Día de organillos también fueron dirigidos por Sergio Bravo y sus años de realización son respectivamente 1958 y 1959. 
hasta el valle de Andacollo, por el vaivén mecánico y orgánico a la vez de los danzantes chinos al compás destemplado de sus flautas, por las rogativas y gracias cantadas de los devotos y, por sobre todo, por el rostro de la imagen de la Virgen que el registro enfatiza como una "visión" en el particular sentido numinoso.

\section{La cámara y la "vivencia"}

En estos filmes, la experiencia reacciona ante los objetos como un dinamismo incorpóreo(fotográfico) o corpóreo (dramático coreográfico), luminoso o material, y es la propiedad emotiva o espiritual de la cámara o del punto de vista la que sella la originalidad formal, dramática o argumental de lo que se propone fílmicamente como documento. Las disposiciones poéticas cinematográficas de estos realizadores recuerdan, en el plano de la no ficción, la sensibilidad de una nouvelle vague futura, y que 10 años antes de estos documentales (1948), por cierto en Francia, advierte el crítico Alexander Astruc en su célebre artículo La caméra-stylo (1998). La libertad tópica y formal de Bravo, Yankovic y Di Lauro, corresponden en sus cinematografías y bajo el influjo de sus experiencias a figuraciones de autoría. Según Astruc "el autor escribe con su cámara de la misma manera que el escritor escribe con una estilográfica" (224). La jerarquía exaltada de la experiencia-idea como orientación de estos documentales expresada en la literalización del diálogo entre dinamismos perceptuales y espirituales con dinamismos escénicos, icónicos, plásticos, a la vez que sintonizada con las ideas de Astruc, precursoras de la "nueva ola" francesa, lo hace también con los requisitos de exposición del pensamiento y emancipación de la forma del paradigma de la "imagen-tiempo" de Deleuze (1996). Como un hecho gestual e ideológico, Astruc precisa que "el acontecimiento fundamental de estos últimos años es la toma de conciencia que está a punto de producirse del carácter dinámico o sea significativo de la imagen cinematográfica" (222).

Ahora bien, sin que la técnica cinematográfica se constituya por su base operativa mecánica como un agente inhibidor de los movimientos sensibles -más bien lo contrario-, ya sea como autoridad cognoscitiva de la vida sensorial, transfiguración estética-artística de esas impresiones, vivencia religiosa, hasta acá nuestras caracterizaciones preliminares del sentido de la experiencia atribuido al enfoque de estos documentales 
reúnen varias de las categorías sobre la comprensión y definición de la experiencia que propone sobre este "tema universal", particularmente en occidente moderno y contemporáneo el filósofo Martin Jay² (2009), falta sólo señalar por adelantado que también concurre, especialmente en el caso de Andacollo el motivo benjaminiano de la experiencia ${ }^{3}$ memorable, en su caso de una crisis de su posibilidad de transmisión, determinado por la facultad de narrar y por la ocurrencia vital del viaje.

La posibilidad de que el asunto de un documental sean las impresiones luminosas que produce una acción artística, el éxtasis de un carnaval religioso o las impresiones dinámicas del tráfico de una ciudad o de un molino de agua -como ocurre respectivamente en los documentales, Día de Organillos, Láminas de Almahue (1961), ambos de Sergio Bravo-, o las posibilidades plásticas que ofrece el fenómeno de la lluvia a una cámara -como en Lluvia (1961) de Aldo Francia-, se deben al debilitamiento del encargo cultural de lo informativo expositivo que había cumplido el documental chileno desde comienzos del siglo XX a través de vistas, noticiarios y documentales, especialmente en función de los tópicos de los actos públicos, como desfiles y funerales, registros de catástrofes, y exposiciones promocionales de frentes productivos. En ese debilitamiento, concurren favorablemente varias crisis, pero particularmente una mediática, que ya debíamos señalar, para dar sentido a nuestra tesis introductoria: el derrumbe de Chile films. Este centro de producción estatal que había sido creado a comienzos de los cuarenta como parte de las acciones de fomento industrial promovidos por los primeros gobiernos radicales en torno a la $\mathrm{Corfo}^{4}$, sucumbe tras el ensayo de un programa de representación modernista de Chile a través de un cine de estudios estandarizado narrativamente en filmes de género y neutralizado iconográfica y culturalmente, en pos de una neutralidad escénica propicia al cosmopolitismo (Cfr. Reveco) ${ }^{5}$. El fracaso se debió a que esta política consistió en obras pobres argumentalmente, deficientes en un sentido técnico que no lograron sintonizar con el gran público y

2 En una formulación general, categorías epistemológica, religiosa, fenoménica somática, estética y mnémica narrativa.

3 Asunto central del ensayo El Narrador de 1936.

4 Corporación de Fomento de la Producción del Gobierno de Chile.

5 Asunto de la Première partie, Tentatives D'industrialisation du cinema 1939-1949 (72-188), en Un cinéma sous tension. Une histoire du cinema chilien 1939-1973, de Roberto Reveco Fissore, tésis de doctorado en Estética, ciencias y tecnologías del cine y el audiovisual, Universidad de Paris VIII, Vincennes, Saint Denis, Francia. 
que resultaron insostenibles en términos financieros $(O p \text {. Cit. })^{6}$. La caída de Chile films no elevó automáticamente el documental a un sitio de popularidad como un efecto de relevo o sustitución -nunca este género ha tenido esa suerte, ni entonces ni ahora-, pero contribuyó a liberar a la no ficción, y a algunas ficciones inmediatamente sucesivas como Tres miradas a la calle (1957) de Naum Kramarenco o Morir un poco (1967) de Álvaro Covacevich, de cualquier deber de representación de lo general, de una impresión fílmica de nación o estado, lo que respecto de las actitudes cinematográficas del tema de la razón, social y técnicamente afiatadas, productiva y ascensionalmente, representan una fisura en cierta visión institucional de lo moderno.

La crisis de un gran aparataje como lo fue en cierto modo Chile films con sus instalaciones, flujos de técnicos y directores entre Chile y Argentina, y publicidades de sus proyectos en los magazines de prensa, dejó lugar para lo minúsculo, para la exposición de nuevos pequeños centros dramáticos y escénicos, justamente en el ámbito de esa especie de "literatura menor" que es el documental en el contexto del cine como una lengua (Pasolini 1970), y más aún como lengua personal, como habla volcada sobre lo subjetivo. Mientras la contingencia y la cultura nacional no se politizaran con la intensidad y amplitud propia de la segunda mitad de los sesenta, fracasada la política del cine de estudios como fallo de una política de Estado, el cine no tendría el deber de asumir la responsabilidad de informar o educar en la exposición de Chile. Tal carga, más bien, se le impone como misión o como objetivo de origen a la televisión entregada a las grandes universidades como la Universidad Católica de Valparaíso, la Pontificia Universidad Católica de Chile, y la Universidad de Chile.

\section{Experiencia subjetiva y la "no figuratividad"}

El vuelco hacia lo minúsculo, hacia lo íntimo de la experiencia o a lo periférico territorial que proponemos, representado en los asuntos de Mimbre y Andacollo, corresponden a una suspensión del interés por lo económico o por lo social recién descubierto, que se venía dando en el documental a comienzos de la segunda mitad de los cincuenta, o por lo político

6 Revisar en la Deuxieme partie, Depression et invention d'un nouveau modele, 1950-1966 (190-277) en la tesis ya referida. 
militante desde mediados de los sesenta en adelante (Corro et al., 2007). Los documentales Arica, puerto libre (1955) de Kramarenco, Sewell, ciudad del cobre, (1956) y Caletones, ciudad del fuego, ambos de 1956 y de Patricio Kaulen, o El pino insigne (1956) de Armando Parot, representantes del documental expositivo en clave promocional económica, y Las Callampas (1957) o La cara tiznada de Dios (1963) -ambas del entonces sacerdote jesuita Rafael Sánchez-, son ejemplos de la intervención cinematográfica en el ámbito del gran conflicto social de la falta de vivienda, radicalizado en la década de los cincuenta por la crisis de la industrialización y por las tomas de terreno (Garcés, 2002), y aunque interpretativos en su articulación retórica, no aluden en lo más mínimo a la vivencia personal. Su potencial avance en el sentido de ampliar el repertorio argumental de los territorios sociales, laborales y culturales lesiona la intención de cercanía efectiva visual y narrativa mediante el prejuicio retórico de la voz neutra de sus narradores dispuestos institucionalmente. Menos espacio para la subjetividad, aunque si para la articulación persuasiva del relato, ofrecen documentales como Las banderas del pueblo, película de 1964 de Sergio Bravo destinada a apoyar la campaña presidencial de Salvador Allende, filme umbral del capítulo del documental militante que se sostiene hasta las más dramáticas intensidades argumentales de 1973 (Corro et al. 2007) y que disuelve lo personal en aras del mandato de lo colectivo.

El intervalo de la experiencia que representan Mimbre y Andacollo es precisamente el del experimento de la experiencia articulado a través de la suspensión del narrador en favor del observador, del actante, y especialmente del experimento de la figuración de los efectos de la vivencia a través de las composiciones del montaje afectivo que traduce los impactos sensoriales en dialécticas plásticas y temporales de luz y sombra, de la literalización de la cámara por su movilidad compositiva -narrativamente autónoma y ópticamente revelada por la sobreexposición fotográfica-, pero aún más a través de estructuras musicales que dan sonoridad a esos enfrentamientos figurativos o instalan nuevas jerarquías de palabra a través de las canciones.

Si resultaba sorprendente que antes de nosotros, ya en 1960, la Revista Ecran relacionara el documental religioso de Yankovic y Di Lauro a las obras inmediatamente precedentes de Bravo, más sorprendente es la presencia experimental común que tiene la música de Violeta Parra en Mimbre y Andacollo. Sergio Bravo, en los libros Teoría del cine documental 
chileno, 1957-1973, de Corro, Larrain, Alberdi y van Diest, y en Historia del cine experimental de la Universidad de Chile, de Salinas y Stange, afirma que Violeta Parra, a instancias del secretario general de la Universidad de Chile, Enrique Bunster, vio el material que él, siendo estudiante de arquitectura y ayudante de la cátedra del arquitecto de la Bauhaus Tibor Weiner, había rodado con una cámara de $16 \mathrm{~mm}$ de propiedad del historiador Leopoldo Castedo. La música que compuso, con aires de tonadas y estridencias propias de los modos doctos contemporáneos, muy en la línea de sus "anticuecas" que son de ese mismo año y de los sones de su tonada El gavilán, son una reacción asincrónica a los nudos, curvas de gráficos, caleidoscopios, y latigazos de luz y sombra que siempre en el primer plano producen las manos del artesano con la fibra de mimbre bajo el sol contra la oscuridad del patio taller y en correspondencia con la explicitud de la cámara que se tienta con las desfiguraciones ${ }^{7}$. En cuanto a la composición de Violeta, ésta, a través del glissando de las notas y los acordes, produce precisamente cierta desfiguración de los motivos referenciales de la cueca y la tonada que se corresponde con la metamorfosis de los cuerpos tejidos con mimbre y del cuerpo mismo del artesano a través del seccionamiento de las figuras por el primer plano y los altos contrastes de luz. En algún sentido, esas sacudidas de luz que afectan al documentalista -según la leyenda de obertura del documental-, asimilan la experiencia subjetiva a la no figuratividad.

\section{Música, corporalidad y cronología}

En cuanto a la música de Violeta en Andacollo, ésta le confiere a la experimentalidad del enfoque medio observacional o participativo del filme -de acuerdo a su cercanía o interacción con el objeto que es la virgen o su fiesta-, la figuración de un índice corporal de la experiencia, la narración cantada del camino del peregrino. Como en otros

7 La actividad sensible, en cierto modo autorreferente del objetivo, corresponde a esa práctica de “hacer sentir la cámara" que seis o siete años después de estos documentales (1965), en su célebre conferencia del Festival de Pesaro "Cine de Poesía" reconoce Pasolini como una de las características más sobresalientes de esa nueva actitud lingüística notoria en algunos nuevos cines de Italia y Francia y que a su vez a mediados de los años setenta el filósofo Deleuze eleva hermenéuticamente a índice de una conciencia fílmica nueva al interpretar la patentización del registro por su insistencia escópica como un verdadero "cogito fílmico". 
patrones musicales del documental, como en los filmes de "sinfonías de ciudad"8 a comienzos del siglo XX, la estructura dramática de Andacollo es la de una jornada, aunque la fiesta dure tres días. La cronología es solar, el periplo va del alba al crepúsculo. En la obertura de créditos, mientras sorprenden los grandes planos generales del paisaje nortino y del valle de Andacollo filmados en color desde un avión por Andrés Martorell, asoma el sol detrás de los cerros y su luz -a contraluz- se quiebra como una estrella en el lente de la cámara. Aún más, como evidencia experiencial de la factura subjetiva de la imagen, en el ángulo inferior derecho, extendida sobre el suelo en el sentido interior de la profundidad de campo, se ve la sombra del director de fotografía operando su cámara. Desde ese ángulo bajo, rasante, como para enfatizar la conciencia del suelo, de la tierra en sombras contra el gran margen superior de cielo, aparecen las siluetas de los peregrinos caminantes. Entonces irrumpe la voz de Violeta y sus palabras que son una relación coloquial a la virgen del tiempo de viaje desde la casa al santuario, una inmejorable apelación personal: “De muy lejos nuevamente venimos Doña María a cantarle un esquinazo antes que amanezca el día y unos presentes trajimos, ayayayai, contento y en armonida. Desde mi casa a la suya echan tres horas corridas pero cortando los cerros una hora y media justita y alargando más el tranco, ayayayai, una hora no más Mariquita."

El canto del tiempo de viaje, con las posibilidades de abreviarlo o dilatarlo que permiten la voluntad y el fervor, son índices dramáticos de la experiencia del romero y el devoto, vivencias que facultan el estatuto de homenaje a la "coronada reina de la Montaña" del documental. Sin contradecir la figura y medida cronológica arcaica del caminante que el canto de Violeta y la iconografía enfatizan, la presencia escénica de elegantes automóviles y rústicos camiones que también llevan romeros a la fiesta, asocia al fervor religioso figuras de una cronología moderna. En este sentido, la máquina documental -la cámara y los vehículos

8 Registros documentales que como elogios modernistas de las metrópolis coordinan con sentido musical -o coreográfico y a través del montaje-, la apariencia ubicua de flujos mecánicos y humanos. Ejemplos emblemáticos de estas formas son Berlín sinfonía de una ciudad (1927), de Walter Ruttmann, o Sao Paulo, sinfonía de una metrópolis (1928), de Adalberto Kemeny y Rodolfo Rex. En Chile hemos propuesto como afín a ese paradigma estético y retórico el documental Santiago 1933 de Armando Rojas (Cfr. Corro, 2013). 
mecánicos como "técnicas de cercanía"9 - contribuye a la formalización temporal de lo trascendente ${ }^{10}$. En relación al canto como relato, éste se articula dramática, estética y espiritualmente con el protagonismo de las rogativas y agradecimientos que le cantan los romeros chinos, danzantes y turbantes en el interior del templo, relatos que por la intimidad narrativa y la cercanía de la imagen que proponen mantener con la Santa Madre a través de su detallismo, contrastan con la distancia de la pompa y el tedio del Arzobispo de La Serena que apenas se le nombra en el documental de Yankovic y Di Lauro.

\section{La vista aérea y los nuevos centros}

En relación con la evidencia argumental e icónica del trayecto -que también cifran simbólicamente los danzantes-, y con el índice de cercanía fotográfica de los que declaman en primer plano, certificando el carácter experiencial cordial de su diálogo con la Virgen, conviene detenerse en la función relativa que tienen los grandes planos generales en el documental religioso. La vista aérea de las sierras nortinas próximas a Andacollo -visión con afinidad cartográfica, con intención de mapa afectivo- concilia lo viejo de la fiesta religiosa tradicional con los inventarios visuales de lo nuevo técnico, con el avión, la cámara, los automóviles, la evocación fílmica del mapa, y con lo actual subjetivo, espiritual, la devoción mariana de Yankovic y Di Lauro. En 1959, la aproximación elevada hasta el valle de Andacollo, en un gran plano general donde la catedral aparece majestuosa entre la bruma matinal o la polvareda que levantan los pe-

9 En nuestro proyecto de investigación "Imágenes de técnicas en el cine documental latinoamericano: motivos de modernidad y de territorio", Concurso Puente 2015, Vicerrectoría de Investigación, Pontificia Universidad Católica de Chile, de acuerdo a los planteamientos de este mismo texto, consideramos en los documentales latinoamericanos del siglo XX la persistencia iconográfica y argumental de cámaras de cine, vehículos motorizados y mapas u otros efectos cartográficos, como sistemáticos y contingentes índices de sentido local de territorialidad y de modernidad. A estos motivos técnicos, y bajo la priorización del aspecto ideológico de dominio temporal y espacial que proponen sobre una escena cultural objetiva y local, los denominamos "técnicas de cercanía".

10 La virtud narrativa y argumental de lo contemporáneo y lo arcaico que estos motivos documentales descubren a fines de los años cincuenta, corresponden en gran medida a una disposición creativa y estética que los jóvenes cineastas de entonces como Sergio Bravo, o Nieves Yankovic y Jorge Di Lauro le reconocen a Violeta Parra, quien no sólo innova y experimenta con el folclor, sino que lo dispone objetivamente para interactuar con la moderna técnica cinematográfica y con disposiciones documentales atípicas como la de estos filmes. Ciertas caracterizaciones biográficas recientes de Violeta Parra, como la del filme Violeta se fue a los cielos (2011) de Andrés Wood, han certificado su perfil de artista moderna no sólo a través de la figuración de su versatilidad expresiva, autonomía sentimental, actitud cosmopolita, y compromiso político revolucionario, sino que precisamente asociándola a los nuevos medios y técnicas de comunicación masiva. En el referido filme, Violeta aparece viajando por remotas zonas rurales registrando con un aparato radiofónico las memorias musicales de los mayores, también se presenta en un estudio de radio conduciendo un programa de música chilena, y plenamente cómoda frente a las cámaras en un estudio de la televisión argentina. 
regrinos, se puede relacionar con intención heterodoxa a los descensos aéreos a las grandes ciudades modernas que repiten célebres filmes latinoamericanos para objetar la unanimidad del bienestar y la innovación en las metrópolis, descubriendo en sus núcleos quistes de pobreza, de irracionalidad, de pre-modernidad. Así ocurre con la vista aérea de Río de Janeiro en la obertura del filme Río 40 grados (1955) de Nelson Pereira do Santos, con el panorama elevado de Ciudad de México también en el inicio de Los Olvidados (1950) de Luis Buñuel, y con la vista cenital de Santiago de Chile en la primera escena de Las Callampas (1957) de Rafael Sánchez. La variante representacional del sitio de la modernidad en crisis que Andacollo también revela concertando la cámara y el avión como técnicas de cercanía territorial y social, consiste en que el plano general del valle de Andacollo, elevado fílmica y argumentalmente como periferia histórica y cultural a un centro dramático posible, presenta el acto cinematográfico de la aproximación hacia el corazón del sistema, identificado con la imagen de la Virgen, no como descubrimiento dramático de la labilidad de la razón, sino como más bien como un núcleo irradiante de correspondencias espirituales, de unicidad experiencial.

Ahora bien, aún en relación con el motivo del viaje, del camino en el canto, vale la pena considerar otro aspecto de la noción filosófica de experiencia atraída por estos documentales. De acuerdo con Walter Benjamin en su texto El narrador (2008), lo que decae en la modernidad europea del siglo XX tras la Gran Guerra es la capacidad de comunicar la experiencia vivida. En su idea de la institución tradicional del narrar frente a la inmediatez, la cercanía y la actualidad como principio de la prensa, aquella propone el régimen de la duración y de la distancia de quien ha hecho un viaje o realiza labores tradicionales. Sostiene Benjamín que aquel que ha viajado tiene algo que contar, algo que es propio a su experiencia que resulta de su camino pero también de otros, de una senda que ya han hollado muchos. Bien, tal es la función de la experiencia del caminante en Andacollo, la de asimilar la vivencia religiosa a un viaje -el de Yankovic y Di Lauro desde el cielo o el de la virgen que simbólicamente desciende- ${ }^{11}$. El viaje de Andacollo es particular y colectivo, afín a un drama ritual de figurantes sin nombre. La indeterminación informativa del enfoque participativo, observacional o experiencial de la película corresponde a

11 En la historia del cine hay muchas apoteosis representadas en vuelos descendentes. Baste con revisar la llegada de Hitler a Nuremberg en El triunfo de la voluntad (1935). 
su indeterminación dramática de número, vivencia no sólo de uno o de muchos, sino de unos y otros.

Los diez años de producción documental chilena en que se insertan Mimbre y Andacollo (1955-1965), están liberados del punto de vista trascendental expositivo de la nación o el Estado modernizantes -obsesionado por lo nuevo-, y del punto de vista de los trabajadores, pobladores y campesinos que, como mirada históricamente por venir, se interesará en las inversiones del orden político o en la imagen de la refundación material que no es necesariamente siempre la imagen de la innovación.

Para concluir, reconsideramos que la materia prima cinematográfica de estos documentales de experiencia es la luz, el índice físico del medio técnico, el índice dramático del ojo del realizador, del documentalista, el índice fenoménico de la vitalidad como hecho estético o numinoso. La luz es la que sacude perceptual y técnicamente la experiencia.

A modo de epílogo, una consideración histórica. La franja temporal 1957-1959 que comprenden estas películas centradas en las experiencias íntimas de lo estético y lo místico, fue un periodo de profundo escepticismo político. Los años en que el proyecto populista de Ibañez, que venía a superar la decadencia de los partidos, se derrumba por la inflación y la incertidumbre de las rotativas ministeriales (Correa et al. 197). Antes de que se imponga el economicismo gerencial del gobierno de Alessandri (205), el vacío de las imágenes políticas determinantes se suma al fracaso del proyecto estatal del cine y cede a las conciencias fílmicas experimentales como las examinadas en este texto, un espacio, un vacío, un margen, una pausa para aventurar con una subjetividad sin fines edificantes. 


\section{Referencias Bibliográficas}

Arica puerto libre. Dir. Kramarenco, Naum. 1955. Medio fílmico.

Andacollo. Yankovic, Nieves y Di Lauro, Jorge. 1958. Medio fílmico.

Astruc, Alexander. Nacimiento de una nueva vanguardia: la "Camérastylo". Textos y manifiestos del cine. Eds. Joaquim Romaguera y Homero Alsina. Madrid: Cátedra, 1998. Medio impreso.

Berlín, sinfonía de una ciudad. Ruttmann, Walter. 1929. Medio fílmico.

Bazin, André. ¿Qué es el cine? Madrid: Rialp, 2012. Medio impreso.

Benjamin, Walter. El Narrador. Introducción, traducción, notas e índices de Pablo Oyarzún R. Santiago de Chile: Ediciones Metales Pesados, 2008. Medio impreso.

Caletones, ciudad del fuego. Parot, Armando. 1956. Medio fílmico.

Corro, Pablo et al. Teorías del cine documental chileno, 1957-1973. Santiago: Pontificia Universidad Católica de Chile, 2007. Medio impreso.

Correa, Sofía et al. Historia del Siglo XX chileno. Santiago. Editorial Sudamericana, 2001. Material impreso.

Día de organillos. Bravo, Sergio. 1959. Medio fílmico.

Deleuze, Gilles. La imagen-movimiento. Buenos Aires: Paidós, 2008. Medio impreso. . La imagen-tiempo. Buenos Aires: Paidós, 1996. Medio impreso.

El pino insigne. Parot, Armando. 1956. Medio fílmico.

Garcés, Mario. Tomando su sitio. Santiago: Lom, 2002. Medio impreso.

Jay, Martin. Cantos de experiencia. Variaciones modernas sobre un tema universal. Buenos Aires: Paidós, 2009. Medio Impreso.

La cara tiznada de Dios. Sánchez, Rafael (S.J.). 1963. Medio fílmico.

Las banderas del pueblo. Bravo, Sergio. 1964. Medio fílmico.

Las callampas. Sánchez, Rafael (S.J.). 1957. Medio fílmico.

Láminas de Almahue. Bravo, Sergio. 1961. Medio fílmico. 
Los olvidados. Buñuel, Luís. 1950. Medio fílmico.

Lluvia. Francia, Aldo. 1961. Medio fílmico.

Mimbre. Bravo, Sergio. 1957. Medio fílmico.

Morir un poco. Covacevich, Álvaro. 1967. Medio fílmico.

Pasolini, Pier Paolo. "Cine de poesía”. Pier Paolo Pasolini contra Eric Rohmer. Cine de poesía contra cine de prosa. Barcelona: Anagrama, 1970. Medio impreso.

Reveco, Roberto. Un cinéma sous tension. Une histoire du cinema chilien 1939-1973. Tesis doctoral en Estética, ciencias y tecnologías del cine y el audiovisual. Universidad de Paris VIII, 2015. Vincennes, Saint Denis, Francia.

Río, 40 grados. Pereira do Santos, Nelson. 1955. Medio fílmico.

Santiago 1933, Rojas, Armando. 1933. Medio fílmico.

Sao Paulo, sinfonía de una metrópolis. Kemeny, Adalberto y Rex, Rodolfo. 1928. Medio fílmico.

Salinas, Claudio y Stange, Hans. Historia del Cine Experimental en la Universidad de Chile, 1957-1973. Santiago: Uqbar editores, 2008. Medio impreso.

Sewell, ciudad del cobre. Kaulen, Patricio. 1956. Medio fílmico.

Tres miradas a la calle. Kramarenco, Naum. 1957. Medio fílmico.

Vega, Alicia. Itinerario del cine documental chileno: 1900-1990. Santiago: Universidad Alberto Hurtado, 2006. Medio impreso.

Violeta se fue a los cielos. Wood, Andrés. 2011. Medio fílmico. 